\title{
The Perceptions of the Best Portuguese Coaches about Dropout and Persistence in Women's Artistic Gymnasts
}

\author{
Artur Pereira ${ }^{1}$, Ana Faro ${ }^{1}$, David Stotlar ${ }^{2} \&$ António Manuel Fonseca ${ }^{3}$ \\ ${ }^{1}$ FCDEF, Universidade de Coimbra, Portugal \\ ${ }^{2}$ School of Sport \& Exercise Science; University of Northern Colorado, USA \\ ${ }^{3} \mathrm{CIFI}^{2} \mathrm{D}$, Faculdade de Desporto, Universidade do Porto, Portugal \\ Correspondence: Artur Romão Pereira, Faculdade de Ciências do Desporto e Educação Física da Universidade \\ de Coimbra, Estádio Universitário de Coimbra, Pavilhão III, Santa Clara, Coimbra, 3040-156, Portugal. Tel: \\ 351-239-802-770. E-mail: arturromao@fcdef.uc.pt
}

Received: March 25, 2014

Accepted: April 28, $2014 \quad$ Online Published: May 20, 2014

doi:10.5539/ijps.v6n2p74

URL: http://dx.doi.org/10.5539/ijps.v6n2p74

\begin{abstract}
The purpose of the present investigation was to study the perceptions of the best Portuguese coaches of women's artistic gymnastics on athletes' persistence and dropout behaviors. Semi-structured interviews were applied to obtain the coaches' $(\mathrm{n}=8)$ accounts on why athletes persisted in or dropped out of gymnastics, and what lead parents to maintain or remove their daughters from gymnastics. In both cases, two distinct time periods were distinguished: "at the beginning of the career" and "throughout the career". Additionally, coaches were also questioned as to the factors underlying athletes' success in gymnastics. Results showed that, in the opinion of coaches, the decision to dropout or persist, whether it emanated from the athletes or their parents, stemmed from multiple causes. Nevertheless, the rigorous physical and psychological demands of the training process, and the conflict of those demands with work, study and family commitments, were often strong motives for athletes' and parents' dissatisfaction. Contrariwise, the enjoyment derived through the involvement in gymnastics, competitive ambition and the experience of success were some of the main motives attributed to athletes' persistence in gymnastics. Regarding parents, gymnastics began as a way to fill up their daughters' free time and as a means to promote their comprehensive education. However, in time, gymnastics seemed to become a means of social affirmation and an outlet for parents' personal frustrations. Finally, coaches stressed the importance, for success in women's gymnastics, of successful competitive results and enjoyment, as well as the human and social circumstances surrounding the athletes.
\end{abstract}

Keywords: coaches, dropout, parents, persistence, success, women's artistic gymnastics

\section{Introduction}

The factors influencing the selection, development and stability of competitive athletes assume a crucial and decisive role in the success of their sporting career. To that extent, successful sport organizations need to implement and manage, strategically, a multifaceted structure that supports the whole training process. This structure can not only bring greater consistency to the career development of athletes, but also minimize the impact of possible entropy factors that may hinder their performance. In this context, a thorough understanding of what influences athletes' performance - particularly with regard to the motivational factors that keep some athletes committed, inspiring and encouraging them to surrender as much as possible, while others decide to terminate their involvement in sports - can help improve the structural and human conditions essential to optimize the training and learning process and, ultimately, athletes' sports performance (Nunomora, Okade, \& Carrara, 2012; Weiss \& Hayash, 1995).

From one point of view, the dropout phenomenon has always been a major concern for all those who, directly or indirectly, invest in youth sports development. Over the years, numerous investigations have sought to investigate the causes of dropout in organized sport, concluding on the non-existence of a single reason to explain that decision. Furthermore, the frequency of the multiple reasons evoked to justify dropout from sport varied from study to study (Lindner, Johns, \& Butcher, 1991). However, conflicts of interest (e.g., school, work), other interests, excessive emphasis on competition, boredom, competitive stress, conflict/ negative coach 
experiences, and lack of fun were consistently amongst the most common dropout reasons mentioned in the research literature (Johns et al., 1991; Weiss \& Williams, 2004). Additionally, several studies have shown that the number of children who discontinue their participation in sport increases as they get older. At this level, adolescence age, characterized by major physical alterations, transformations toward life independency and individuality, and by a growing awareness of alternatives to their lifestyle, is the period of greatest risk for dropping out of sport (Delorme, Chalabaev, \& Raspaud, 2011; Gould \& Whitley, 2009).

On the other hand, attempts to study the reasons why athletes persist in sport are also abundant (Fonseca, Corte-Real, \& Dias, 2010; Fraser-Thomas \& Côté, 2009). Indeed, as important as having children begin a sport-which, given the natural interest and motivation they usually demonstrate regarding sport practice, is not difficult-is to keep them interested and committed to that practice (Le Bars, Gernigon, \& Ninot, 2009; Nunomora et al., 2012). Accordingly, several studies have investigated individual differences in various psychological characteristics between young athletes who persist and those who end their involvement in sport. The results of some of these investigations showed that the former reported that their coaches, parents and even peers emphasized the learning process and the attainment of mastery through effort (LeBars et al., 2009; Sarrazin, Vallerand, Guillet, Pelletier, \& Cury, 2002), and described higher satisfaction of the basic psychological needs for relatedness and autonomy, and lower levels of amotivation and extrinsic motivation (external regulation, and introjected regulation) (Calvo, Cervello, Jiménez, Iglesias, \& Murcia, 2010).

In the specific case of women's artistic gymnastics, the sport in which the present research was developed, motivation assumes an overriding importance. According to Smolevskiy and Gaverdovskiy (1996), an athlete cannot achieve success in this sport without an adequate level of motivation. Athletes have to perform very complex tasks, often more complex than the tasks they perform in their everyday lives, requiring a commitment that, in terms of volume and intensity, can reach six hours per day (Arkaev \& Suchilin, 2004). Hence, to achieve high levels of performance, they must remain motivated and consistently committed to the whole process (Khan, Haider, \& Ahmed, 2011; Munkácsi, Kalmar, Hamar, Katona, \& Dancs, 2011).

Therefore, the knowledge of the factors that influence athletes to leave or to persist in women's gymnastics, as well as the level of influence exerted by each of them, should be seen as a key component of the management of any club. This knowledge can preventively alert for possible risk behaviors that suggest the intention to dropout sport, ultimately preventing that the enormous emotional and financial investment made toward athletes' training results in failure. In one of the few studies comparing motivational determinants of athletes who abandoned women's artistic gymnastics with others who persisted, Ryska, Hohensee, Cooley, and Jones (2002) concluded that six predictors distinguished participants from dropouts: in comparison to those who persisted, dropout gymnasts tended to be older and were involved in competitive gymnastics for situational (e.g., get out of the house) and social recognition reasons (e.g., be popular or feel important), that is, extrinsic motives. In contrast, gymnasts who persisted were more intrinsically motivated, continuing their participation for motives associated with physical fitness (e.g., stay in shape), personal challenge (e.g., learn new skills), and team atmosphere (e.g., like the team spirit).

Additionally, research within the socialization literature recognizes the important role of significant others, including coaches/ teachers, parents and teammates, in supporting and shaping children's attitudes towards participation in sport (Fredricks \& Eccles, 2004; Weiss \& Hayashi, 1995). Parental support is seen as a crucial factor influencing not only the children's decision of practicing a particular sport, but also the development of their sporting careers (Fraser-Thomas, Côté, \& Deakin, 2008; Wuerth, Lee, \& Alfermann, 2004). This support is especially relevant during childhood, since, throughout this period, parents are the main and often only source of emotional and financial sustenance, providing the necessary means and resources for children to remain in sport. In the specific case of artistic gymnastics, children start at very low ages, which further subordinates the practice of this sport to parents' interest and availability. Without their socio-emotional, financial, and even logistical assistance, it would be very difficult, or perhaps impossible, for a gymnast to achieve success (Cogan \& Vidmar, 2000; Nonomura \& Oliveira, 2008).

Nonetheless, young gymnasts seem to be aware of the positive attitudes, expectations and behaviors of their parents, and these, in turn, recognize the positive consequences that occur within the family, and for themselves, as a result of the intense involvement of their daughters in gymnastics (Weiss \& Hayashi, 1995). In other words, despite the extra time and financial investment in the sport experience throughout athletes' infancy and childhood, children and their parents are able to perceive positive family interactions in connection with the practice of gymnastics. Along the same lines, most of coaches believe that parental involvement usually results in positive child outcomes, with only a minority negatively influencing their child's development. Accordingly, coaches and sport administrators should not avoid or minimize the interactions between coaches and parents 
(Gould, Lauer, Rolo, Jannes, \& Pennisi, 2008). Such behavior could result in to neglect rich and potentially important information regarding the athlete, the training process and even a possible intention to dropout sport (and to determine who is behind that intention, the child or the parents). In fact, whilst it is accepted that the family has a say in that regard (i.e., in the decision to dropout the sport), few studies have examined this impact in detail (Fredricks \& Eccles, 2004).

Based upon the previous review, the present study aimed to examine the perceptions of the best Portuguese coaches of women's artistic gymnastics on the reasons underlying the decision of some young athletes to discontinue their involvement in the sport, and the motives why other athletes remain committed, over time, to this activity. In the same vein, the perceptions of coaches regarding the reasons that cause parents to cease their daughters' participation on artistic gymnastics, and, in contrast, the motives underlying other parents' decision to keep their children involved in the sport were also studied. Also, considering that the decision to persist or dropout the sport orbits around athletes and their parents, two different moments of influence were taken into consideration: "at the beginning of the sport career" and "throughout the sport career". The first moment concerns the period on which the athlete experiences a generic commitment to gymnastics, and is embodied by an activity based on a form of exploratory recreation. The moment designated as "throughout the sport career" regards the long-term competitive career on which the athlete made a full commitment to the sport, thus being associated with a deliberate investment and a specialization process. In this regard, numerous researchers advocate that competitive success is largely conditioned by a robust long-term investment, taking between eight to 12 years for a talented athlete to achieve excellent results in sport (Bloom, 1985; Ericsson \& Charness, 1994). Finally, considering that, in a previous study by Pereira, Faro, Stotlar, and Fonseca (2013), the Portuguese artistic gymnasts who achieved the best results at the senior level had consistently been champions at lower age levels - which suggests a good optimization of those athletes who showed better potential when they were taking their first steps in the sport-his research also examined the perceptions of coaches regarding the factors that would justify this success in spite of all the difficulties that characterize the practice of women's artistic gymnastics in the Portuguese sport context.

\section{Method}

\subsection{Participants}

To participate in this research, coaches were required to have worked with athletes who had officially represented the Portuguese Gymnastics Federation (PGF) at international competitions between the years of 1971 and 2011. Eleven coaches met this condition. However, as one of those coaches is the principal author of this research, and two did not reply to several contact attempts, only eight coaches (five females and three males) participated in this investigation. Still, it should be noted that this number represented $72.7 \%$ of the universe of coaches who meet the predefined requirements. The average number of years coaches reported coaching gymnastics was 26.4. Four of them had been involved in the Olympic games as coaches, each with an athlete. All the others had worked with athletes who participated in World Championships, European Championships and several official international competitions. Each coach had won over 10 individual national titles. Finally, it is worth noting that seven of the eight coaches had had management functions in clubs, associations, and even in the International Gymnastics Federation (Fédération Internationale de Gymnastique [FIG]).

\subsection{Interview Guide}

Semi-structured, open-ended interviews were carried out using a three-section interview guide specifically created for this study. The interview began with a brief introduction, in which the interviewer provided information about the general purpose of the project and clarified any doubts. Next, the interviewer extracted information concerning the coaches' background and athletic experience (e.g., years of experience, main titles at the national and international levels). The rest of the interview guide consisted of key questions regarding the perceptions of coaches on (a) the reasons underlying the decision of athletes to dropout women's artistic gymnastics and the motives that lead other athletes to remain involved in this sport, (b) the reasons that cause parents to discontinue their daughters' participation, and the motives why others maintain their children involved in gymnastics, and (c) the causes that could explain why successful Portuguese athletes at the senior levels had also been successful at lower age levels.

\subsection{Pilot Interview}

Two pilot interviews were conducted (and audio taped) individually with a Portuguese female gymnastics coach. This coach was recognized as a specialist in high level coaching by PGF and Portuguese Olympics Committee. The pilot interview tested for appropriateness and comprehension of questions and terms and was conducted individually by the leading researcher. Based on the coach's feedback, and also on the leading researcher 
evaluation, modifications were made to adjust the wording of the questions to the specificities of high performance gymnastics.

\subsection{Data Collection and Analysis}

As previously mentioned, a semi-structured open-ended interview was specifically developed for this study. In an initial phase, and with the intention of obtaining a comprehensive view of the coaches' perceptions, maximum freedom of expression was granted. Subsequently, data collected from these interviews were subjected to content analysis. This content analysis allowed for the exploration of themes related to the dropout or persistence in gymnastics, distinguishing, sorting and grouping the answers in an organized system of categories (i.e., items), which, after being complemented by a literature review, supported the second phase of the data collection. At this stage, respondents were asked to rate the relevance of each category on a scale provided by the interviewer (Kerlinger, 1980), ranging from 1 (=Not relevant) to 6 (=Extremely relevant). If the coaches considered that a given item was not relevant, they could move on to the next question. They were also given the opportunity to present other items deemed important. The first author interviewed all coaches individually. Anonymity and confidentiality were assured. The interviews were audiotaped and their average duration was 150 minutes.

\section{Results and Discussion}

\subsection{Reasons for Dropout in Women's Artistic Gymnastics}

In the opinion of the coaches, athletes dropped out women's artistic gymnasts for multiple and rather distinct reasons, both at beginning and throughout their sport career (Table 1). When athletes first became involved in gymnastics, those reasons were mainly associated with the training demands, namely its volume and intensity, the effort and physical and psychological sacrifices the coaches demanded from the athletes, and the fear of performing certain movements. In general, the coaches felt that these difficulties persisted throughout the gymnasts' career, but they also emphasized the importance of health problems and injuries for dropping out at a later stage.

The allusion to reasons associated with the workout regimen is not surprising, inasmuch as any competitive sport necessarily demands an intense commitment to a training program capable of improving athletes' current performance and, ultimately, preparing them for competing at the elite levels (Côté, Young, North, \& Duffy, 2007). As is generally known, women's artistic gymnastics training is particularly arduous and intense. According to specialists, the hours of training have tripled from 2-hour training a day in the 30s to 5-6 hours a day in the modern era (Cuk, Pajek, Jakse, Pajek, \& Pecek, 2012). This workload reflects the need for a high volume of continuous repetitions, namely regarding some especially difficult movements that the athletes are expected to perfect (Arkaev \& Suchilin, 2004; Nunomura et al., 2012).

However, there is also the other side of the coin and the strictness of the training regimen - specially in competitive contexts where the quality of performance is clearly emphasized, such as artistic gymnastics - may be partly accountable for athletes' dissatisfaction, burnout, and dropout (Côté et al., 2007). Moreover, since the essence of women's gymnastics results in large part from the difficulty of the exercises and routines athletes have to perform, they have to learn to live with the risk to their physical integrity. It is thus understandable that the fear in performing certain elements is present not only when athletes start artistic gymnastics but also throughout their career, influencing their motivation and eventually causing some athletes' dropout the sport. In fact, when children start artistic gymnastics, they usually aren't prepared to the severity and the difficulty of the acrobatics they will have to perform. In a study by Nunomura et al. (2012), for example, Brazilian gymnastics coaches reported that when athletes first enrolled in gymnastics they believed it would be easy to learn its complex moves and routines, but got very disappointed when they realized the process took longer than expected. Additionally, considering that weekly time in training, with all the physical problems associated, increases with age and level of competition (Malina et al., 2013), it is not surprising that the coaches in the present study considered that the circumstances of the demanding and rigorous training, as well as injuries, health problems, and relationship problems with teammates and the coach constituted important reasons for attrition at a later stage in athletes' careers.

Other reasons for dropout (indirectly) associated with the intense training of gymnastics, were the reluctance of athletes to accept the lack of time for themselves and the difficulty of balancing sports and school. These problems did not seem to wane with time, since athletes continued to have difficulties prioritizing their time during the course of their career, at least according to their coaches. Specifically, coaches mentioned that the challenges to academic performance and the necessity to deal with new and numerous requests and interests - two reasons that had not been considered at an earlier stage of athletes' career -, became two of the main reasons for the athletes to leave artistic gymnastics later. These results are consistent with most of the 
investigations on the phenomenon of sport dropout among children and youth, in which conflicts of interest (school, work) and other interests consistently and repeatedly emerge amongst the most common dropout reasons (Fonseca, et al., 2010; Lindner, Johns, et al., 1991; Weiss \& Williams, 2004). Furthermore, the research literature also indicates that, as children get older, these specific reasons become more relevant (Butcher, Lindner, \& Johns, 2002).

Additionally, the coaches stressed that, as athletes were advancing in their careers and obviously getting older, the physical and developmental changes associated with pubertal development, eating attitudes and weight gain became issues of prime concern among the gymnasts. Along the same lines, some evidence sustains that the difficulty of the routines, in relation to the postural control and balance of gymnasts, will benefit shorter and lighter athletes (Louer, Elferink-Gemser, \& Visscher, 2012). Accordingly, female gymnasts who persist in artistic gymnastics through adolescence are shorter and later maturing than those who dropout (Lindner, Caine, \& Johns, 1991; Malina, 1999; Malina et al., 2013).

Finally, coaches thought that, as athletes' sporting careers progressed, several competition factors such as the lack of competitive success or achievement of goals and objectives and competitive pressure, conditioned athletes' persistence in gymnastics. Watts (2002) argues that younger practitioners are subject to the same pressures and demands faced by adults, and may have the same difficulties in overcoming the stress of the competitive environment. The selective process inherent in competitive sport and the competition between gymnasts may well frustrate those who do not achieve the same level of development, who continuously fail, or do not achieve their goals, that is, those whose results fall below the expectations (theirs and others) (Nunomura et al., 2012). This is especially important if we consider, as mentioned before, that the level of difficulty of the routines and the training intensity, as well as the pressure of the competition, continue to increase over time, namely for those who want to be elite athletes (Louer et al., 2012).

Table 1. Reasons for dropout in women's artistic gymnastics (athletes)

\begin{tabular}{|c|c|c|c|c|c|c|c|c|c|c|c|c|c|c|}
\hline \multirow{3}{*}{ Categories } & \multicolumn{7}{|c|}{ At the beginning of the career } & \multicolumn{7}{|c|}{ Throughout the career } \\
\hline & \multicolumn{6}{|c|}{ Frequency } & \multirow[t]{2}{*}{$M$} & \multicolumn{6}{|c|}{ Frequency } & \multirow[t]{2}{*}{$M$} \\
\hline & 6 & 5 & 4 & 3 & 2 & 1 & & 6 & 5 & 4 & 3 & 2 & 1 & \\
\hline high volume and intensity of training & 2 & 5 & 1 & & & & 5.1 & 3 & 4 & & & 1 & & 5.0 \\
\hline training demands (effort and sacrifice) & 2 & 2 & 3 & 1 & & & 4.6 & 3 & 4 & & & 1 & & 5.0 \\
\hline lack of personal time & & 6 & 2 & & & & 4.8 & 2 & 4 & 1 & & 1 & & 4.8 \\
\hline fear of performing certain movements and routines & 2 & 4 & 1 & & & 1 & 4.6 & & 7 & 1 & & & & 4.9 \\
\hline poor group integration (teammates) & & 2 & 1 & & 2 & 3 & 2.6 & & 2 & 3 & & 3 & & 3.5 \\
\hline problems in the relationship with the coach & 2 & & 2 & 1 & 2 & 1 & 3.5 & 2 & 2 & 1 & 1 & 2 & & 4.1 \\
\hline difficulties balancing sport and school & 4 & 3 & & & 1 & & 5.1 & 4 & 4 & & & & & 5.5 \\
\hline difficulties maintaining a good academic performance & $\ldots$ & $\ldots$ & $\ldots$ & $\ldots$ & $\ldots$ & $\ldots$ & $\ldots$ & 4 & 2 & 2 & & & & 5.3 \\
\hline goal attainment issues & & 4 & 1 & & 3 & & 3.8 & 1 & 3 & 3 & & 1 & & 4.4 \\
\hline competitive pressure & 2 & & 3 & 1 & 2 & & 3.9 & 1 & 2 & 4 & 1 & & & 4.4 \\
\hline lack of competitive success & 1 & 2 & 1 & & 4 & & 3.5 & 1 & 4 & 3 & & & & 4.8 \\
\hline health problems & $\ldots$ & $\ldots$ & $\ldots$ & $\ldots$ & $\ldots$ & $\ldots$ & $\ldots$ & 2 & 3 & 2 & 1 & & & 4.8 \\
\hline injury related-problems & $\ldots$ & $\ldots$ & $\ldots$ & $\ldots$ & $\ldots$ & $\ldots$ & $\ldots$ & 1 & 3 & 2 & 2 & & & 4.4 \\
\hline somatic development & 2 & & 3 & & 2 & 1 & 3.6 & 1 & 4 & 1 & 2 & & & 4.5 \\
\hline diet & 1 & 1 & 2 & 1 & 2 & 1 & 3.4 & 1 & 2 & 3 & 1 & 1 & & 4.1 \\
\hline weight control & 2 & 2 & & & 3 & 1 & 3.6 & 2 & 4 & & & 2 & & 4.5 \\
\hline injury occurrence & & 4 & 3 & & 1 & & 4.3 & 1 & 4 & 3 & & & & 4.8 \\
\hline other interests & $\ldots$ & $\ldots$ & $\ldots$ & $\ldots$ & $\ldots$ & .. & $\ldots$ & 2 & 5 & 1 & & & & 5.1 \\
\hline
\end{tabular}

Note. Respondents were asked to use the following scale: 6- extremely relevant; 5- very relevant; 4- relevant; 3neither relevant nor irrelevant; 2- slightly relevant; 1- not relevant 
As regards the perceptions of coaches about the reasons why parents suspend the involvement of their daughters in competitive gymnastics (Table 2), the rigorous training regimen emerged, once again, as a major obstacle to the persistence of athletes in the sport. Specifically, the coaches stressed that many parents had problems in accepting the high number of daily hours their daughters spent training and the effort they had to sustain in each and every training session, either when athletes started gymnastics or all through their career. These results reflect the previously analyzed highly specific and demanding training of women's artistic gymnastics basically confirming what it was mentioned before: artistic gymnastics training demands a high volume of repetitions in order to reach perfection and compete at the highest levels, but this intensity and arduousness can also promote early dropout. Moreover, various parents use to express concerns about the risk of injury and other health implications of their daughters' involvement in gymnastics. Curiously, it seems that parental concerns about the risk posed by practicing sport is not exclusive to gymnastics: Boufous, Finch, and Bauman (2004) found that over $25 \%$ of parents prevented or discouraged their children, aged 5 to 12 year, from playing a particular sport because of injury and safety concerns. In boys, the most frequently discouraged sport was rugby and Australian Rules football; for girls, the most frequently discouraged activities were rollerblading, rugby and soccer.

Other training related reasons for dropout were the reluctance of parents to accept the decrease of family time, and the difficulties in coordinating their schedules with their daughters' training schedules, as well as training and school, and the whole family instability therefrom stirred. Especially when children are younger, parents play a key role in supporting and facilitating their sport practice. Amongst other things, they can give them positive feedback, encourage their involvement, provide financial support and transportation, or attend competitions (Fredricks \& Eccles, 2004). In women's artistic gymnastics, all this investment and the expectations created around athletes' performance clearly influence the family dynamics (Malina et al., 2013), and if parents are not able to deal with all the challenges involved, it may cause them to discourage and even discontinue their children's participation in sport.

An interesting finding emerged from the comparison of the reasons that influence parents to suspend the participation of their daughters in gymnastics at the beginning and along their career that, in general, seem to lose relevance with time. These differences may be related to a gradual emancipation of athletes who, when growing, became more autonomous and independent from their parents. Indeed, the important role played by parents as regards children's sport participation at very early ages becomes less relevant as they grow, mature and develop, and, when they enter in the adolescence, coaches and peers usually play a more prominent role than parents (Fredricks \& Eccles, 2004). Additionally, there might have been a learning process involved, as the urgent need to adapt to a new reality of life may have favored in parents the learning of new strategies to deal with their initial concerns and difficulties, and a greater capability to adjust and deal with a renewed family dynamic.

In fact, coaches considered that only two categories (i.e., regarding the difficulties and problems that some parents had in the relationship with the coach and the coaching staff, as well as the suffering experienced in the course of their daughters' competitions) were more important for discontinuing athletes' sport participation throughout the career than at the beginning (although it should be noted that, in absolute terms, these categories were not amongst the most relevant). On the one hand, the fact that the relationship with the coaching staff assumed a greater importance as time passed may reflect the natural wear and tear associated with parents' dissatisfaction with the different circumstances typifying the participation of athletes in this sport. At this level, and in addition to all the factors previously analyzed, it can also be posited that the parents cannot handle the fact that their importance diminishes while an increasingly strong interdependence between the coach and their daughters emerges (Jowett \& Timson-Katchis, 2005). On the other hand, the parents' difficulty in dealing with the distress felt when observing their daughters competing, and its slight increase since athletes first began practicing gymnastics, can be related to the fact that, in seeking an increasingly high score, the routines presented by the gymnasts (and their coaches) have, in recent years, become increasingly difficult, complex and even dangerous. Indeed, since the introduction, in 2006, of the open-ended code of points, the proportion of the evaluation parameters related to the exercise content (difficulty and execution) has changed (Čuk, Fink, \& Leskošek, 2012). Specifically, the score of the routine comprises an execution score which evaluates the performance of the routine starting with a base score of 10 points (the judges distract points for every error made), and a difficulty score which now has no base score and is based solely on the difficulty of the routine. This change in the code of points generated more difficult routines, resulting in a higher difficulty score (Louer et al., 2012). In fact, in spite of the fact that the FIG emphasizes that the aesthetic and technical execution must not be compromised by the increase of the difficulty score, it is common to see the exact opposite in competitions. Indeed, there is evidence that, currently, the proportion between difficulty and execution is, on 
apparatus such as pommel horse or high bar, already above 70\% (Čuk et al., 2012). From a certain point of view, this development makes this sport more and more spectacular (Louer et al., 2012), but it also increases its dangerousness and eventually the distress experienced by parents while watching their children competing.

Table 2. Reasons for dropout in women's artistic gymnastics (parents)

\begin{tabular}{|c|c|c|c|c|c|c|c|c|c|c|c|c|c|c|}
\hline \multirow{3}{*}{ Categories } & \multicolumn{7}{|c|}{ At the beginning of the career } & \multicolumn{7}{|c|}{ Throughout the career } \\
\hline & \multicolumn{6}{|c|}{ Frequency } & \multirow[t]{2}{*}{$M$} & \multicolumn{6}{|c|}{ Frequency } & \multirow[t]{2}{*}{$M$} \\
\hline & 6 & 5 & 4 & 3 & 2 & 1 & & 6 & 5 & 4 & 3 & 2 & 1 & \\
\hline high volume and intensity of training & 5 & 3 & & & & & 5.6 & 2 & 4 & 2 & & & & 5.0 \\
\hline less personal and family time & 4 & 3 & 1 & & & & 5.4 & 1 & 4 & 3 & & & & 4.8 \\
\hline difficulties balancing training schedule and personal schedule & 4 & 4 & & & & & 5.5 & & 5 & 2 & & 1 & & 4.4 \\
\hline fear of a negative effect of training on athletes' health & 2 & 4 & 2 & & & & 5.0 & 1 & 3 & 2 & & 2 & & 4.1 \\
\hline fear of a negative effect of training on athletes' growth & & 1 & 4 & & 3 & & 3.4 & 1 & & 2 & & 5 & & 3.0 \\
\hline fear of injuries & 1 & 2 & 4 & 1 & & & 4.4 & 1 & 2 & 3 & & 2 & & 4.0 \\
\hline $\begin{array}{l}\text { difficulties of integration within the environment created by } \\
\text { parents }\end{array}$ & 1 & 1 & 2 & & 2 & 2 & 3.1 & 1 & & 2 & & 4 & 1 & 2.9 \\
\hline problems in the relationship with the coach (technical staff) & 1 & 1 & 2 & & 4 & & 3.4 & 1 & 1 & 3 & 2 & 1 & & 3.9 \\
\hline difficulties balancing sport and school & 3 & 2 & 3 & & & & 5.0 & 1 & 6 & 1 & & & & 5.0 \\
\hline $\begin{array}{l}\text { difficulty coping with the distress experienced during their } \\
\text { daughters' competitions }\end{array}$ & & 2 & 3 & & 3 & & 3.5 & & 2 & 4 & & 2 & & 3.8 \\
\hline financial problems & & 4 & 2 & & 2 & & 4.0 & & 3 & 2 & & 3 & & 3.6 \\
\hline transportation problems & 3 & 2 & 2 & & 1 & & 4.8 & 1 & 2 & 3 & & 2 & & 4.0 \\
\hline changes in the family structure (familiar instability) & 3 & & 4 & & 1 & & 4.5 & 2 & & 4 & 1 & 1 & & 4.1 \\
\hline geographical change of address & 4 & 1 & 1 & & & 1 & 4.9 & 4 & & 1 & & 2 & & 4.5 \\
\hline
\end{tabular}

Note. respondents were asked to use the following scale: 6- extremely relevant; 5- very relevant; 4- relevant; 3neither relevant nor irrelevant; 2- slightly relevant; 1- not relevant

\subsection{Motives to Persist in Women's Artistic Gymnastics}

According to the coaches, the most important motives for athletes to persist in women's artistic gymnastics included, both at the beginning and throughout their career, the genuine enjoyment derived through the practice of gymnastics and through the learning and execution of its specific movements and skills. Competitive ambition and the experimentation of success, as well as the feeling of belonging to a group, were also highly valued (Table 3).

The importance given to enjoyment is consistent with statements by Côte et al. (2007), according to whom it is essential that young athletes enjoy their sporting experience - which must be inherently interesting and satisfying - and be gratified by learning sport specific skills. In the same vein, several investigations have identified fun and enjoyment as one of the main reasons justifying children and youth sport participation (Fonseca et al., 2010; Light \& Lémonie, 2010; Watts, 2000; Weiss \& Williams, 2004). Additionally, enjoyment also emerged in different studies as one of the most salient predictors of the intention to continue playing sport (e.g., Atkins, Johnson, Force, \& Petrie, 2013; Butcher et al., 2002; Ullrich-French \& Smith, 2009).

Regarding competitive ambition, it should be noted that while at the beginning of the athletes' career that ambition was associated both with the chase of an Olympic dream and with the identification with a sports idol. According to Bandura (1969), a role model is anyone who potentially can influence the decisions or behaviors of another individual. In the present study, the importance assumed by these role models when athletes first began practicing the sport supports previous suggestions that role models can be a crucial factor in increasing adolescent girls' participation in sport and physical activity (Vescio \& Crosswhite, 2002). However, the importance of this role model (idol) seemed to fade as athletes' career progressed. In fact, coaches considered that the identification with a sports idol became, in time, one of the least important motives for athletes to persist 
in gymnastics. This result is not necessarily negative, since the gymnasts' idols probably represented mastery models, and not coping models. Indeed, the results of some studies favor the similarity between the model and the observer, holding, with regard to self-efficacy, that coping models (i.e., models who are competent but demonstrate the strategies used to acquire a skill, who make mistakes but overcome obstacles and improve their performance, thus being perceived as more attainable) will be more effective than mastery models (i.e., an expert demonstrating a high level of expertise, but seen as very distant and separated from the athlete; e.g., idols) (Schunk, Hanson, \& Cox, 1987; Vescio, Wilde, \& Crosswhite, 2005).

Moreover, the coaches highlighted the importance of competitive results (competitive success) for athletes to remain motivated to participate in women's artistic gymnastics, either at the beginning or during their career. This result seems to contrast with suggestions by Côté et al. (2007) that, between 6 and 12 years, coaches should emphasize participation rather than performance and minimize competition. However, these authors also recognize that, in sports such as artistic gymnasts, where the peak performance usually occurs before maturation, it may be necessary to promote a performance (and results) directed environment earlier than usual. Still, they also draw attention to the potential costs associated with this type of sporting environment at these early ages (e.g., injuries, burnout, dropout).

Finally, the importance given by coaches, at both analyzed time points, to the feelings of relatedness (i.e., belonging to a group), is consistent both with the theory (Ryan \& Deci, 2000) and empirical evidence (e.g., Calvo et al, 2010; Ulrich-French \& Smith, 2006; Vazou, Ntoumanis, \& Duda, 2006). Fraser-Thomas, Côté, and Deakin (2005) arguing that social relationships with teammates (e.g., friendship, belonging to a group) have positive psychological consequences (e.g., enjoyment, perceived competence, self-esteem), and may even become, in time, as one of the most important reasons for athletes to remain committed and persist in practicing a sport.

In contrast with the motives previously discussed, which were considered important for athletes' persistence since they first enrolled in gymnastics until a more advanced stage in their careers, other factors stood out only as the careers of the athletes progressed. At this level, coaches stressed that artistic gymnastics provided a form of social affirmation, especially within the athletes' group of friends. Indeed, gymnasts' self-esteem seemed to be clearly enhanced not only by successful competitive results, but also by the fact that they had a great dominium over their body, allowing them to perform movements and skills inaccessible to their friends. Along the same lines, it is worth mentioning that several investigations have found that self-esteem was positively associated with the practice of sport (e.g., Erkut \& Tracy, 2002; Slutzky \& Simpkins, 2009), and with the intention to continue sports participation (e.g., Slutzky \& Simpkins, 2009; Ullrich-French \& Smith, 2009).

Finally, coaches also explored the possibility that athletes remained involved in women's artistic gymnastics because this involvement (as long as it is accompanied by relevant competitive results) facilitates their access to university. In fact, this possibility was, at the second time point (i.e., throughout athletes' career), a major motive for athletes' maintenance in the sport. Usually, the access to university requires high grades and high level athletes do not have much extra time to study, thus facing enormous difficulties in ensuring their academic career. However, the Portuguese government offers a special access regimen to higher education through a law decree denominated "High Competition Statute" (Law Decree No. 125/ 95 of May 31 $1^{\text {st }}$, modified by the Law Decree No. 123/ 96 of August $10^{\text {th }}$ ). Specifically, this statute rewards athletes who achieve excellent competitive results with a prompt access to the university. 
Table 3. Motives to persist in women's artistic gymnastics (athletes)

\begin{tabular}{|c|c|c|c|c|c|c|c|c|c|c|c|c|c|c|}
\hline \multirow{3}{*}{ Categories } & \multicolumn{7}{|c|}{ At the beginning of the career } & \multicolumn{7}{|c|}{ Throughout the career } \\
\hline & \multicolumn{6}{|c|}{ Frequency } & \multirow[t]{2}{*}{$M$} & \multicolumn{6}{|c|}{ Frequency } & \multirow[t]{2}{*}{$M$} \\
\hline & 6 & 5 & 4 & 3 & 2 & 1 & & 6 & 5 & 4 & 3 & 2 & 1 & \\
\hline enjoyment in performing the movements and skills of wag & 5 & 3 & & & & & 5.6 & 4 & 3 & 1 & & & & 5.4 \\
\hline fascination with the uniforms and music routines & & 5 & 1 & 1 & 1 & & 4.3 & 1 & 2 & 4 & & 1 & & 4.3 \\
\hline ambition of being like an idol & 1 & 5 & 2 & & & & 4.9 & 1 & 3 & 2 & & 2 & & 3.6 \\
\hline competitive ambition (associated to the Olympic games) & & 6 & 2 & & & & 4.8 & 1 & 3 & 4 & & & & 4.6 \\
\hline experiencing competitive success & 1 & 3 & 3 & & 1 & & 4.4 & 1 & 4 & 2 & & 1 & & 4.5 \\
\hline feeling of belonging to a group & & 5 & 1 & 1 & & 1 & 4.1 & & 4 & 2 & & 2 & & 4.0 \\
\hline gymnastics as a mean of social affirmation & & 1 & 3 & 1 & 1 & 2 & 3.0 & & 3 & 3 & & 2 & & 3.9 \\
\hline enhanced self-esteem (standing out in the group of friends) & & 3 & 1 & 1 & 3 & & 3.5 & 1 & 1 & 4 & & 2 & & 3.9 \\
\hline $\begin{array}{l}\text { gymnastics as a mean of escaping from harmful environments to } \\
\text { personal stability and happiness }\end{array}$ & & 3 & 3 & & 1 & 1 & 3.8 & 1 & 3 & 2 & & 2 & & 4.1 \\
\hline genuine enjoyment in practicing gymnastics & 2 & 4 & 1 & 1 & & & 4.9 & 2 & 3 & 2 & 1 & & & 4.8 \\
\hline possible financial benefits & $\cdots$ & $\cdots$ & $\cdots$ & $\cdots$ & $\cdots$ & $\cdots$ & & 1 & 2 & 1 & & 2 & 1 & 3.6 \\
\hline possible facilitated access to the university & $\cdots$ & $\cdots$ & $\cdots$ & $\cdots$ & $\cdots$ & $\cdots$ & & 2 & 5 & & & 1 & & 4.9 \\
\hline possible social benefits & $\ldots$ & $\ldots$ & $\ldots$ & $\ldots$ & $\ldots$ & $\ldots$ & & & 2 & 2 & & 4 & & 3.3 \\
\hline
\end{tabular}

Note. Respondents were asked to use the following scale: 6- extremely relevant; 5- very relevant; 4- relevant; 3neither relevant nor irrelevant; 2- slightly relevant; 1- not relevant

With regard to the motives that lead parents to keep their daughters in women's artistic gymnastics (Table 4), the coaches stressed that, at first, gymnastics was a way for parents to fill up their daughters' free time. However, they also believed that the parents recognized the potential of the sport as regards the comprehensive formation of their children and, specifically, the development of their conditional and coordinative abilities. Likewise, an investigation by Kunješić (2012) showed that parents valued the fact that gymnastics helped their children develop motor skills and remain healthy. On the other hand, in the present study there was a decline, throughout athletes' career, in the importance given to the potential of artistic gymnastics regarding the comprehensive education of athletes. However, considering the previously mentioned demands of artistic gymnastics training (workload, sacrifice) - which coaches considered one of the primary reasons for athletes to leave this sport, either by their own initiative or by parents' behest - his result could reasonably be expected. Furthermore, the fact that the reference to gymnastics as a way to fill up athletes' free time, so valued earlier, completely disappeared in a later stage reinforces this interpretation.

Coaches also highlighted the ambition of many parents who wish for their children to become champions. Along these lines, the practice of artistic gymnastics was seen as a means of social affirmation and as an outlet for parents' personal frustration. Unfortunately, it is relatively common for parents to seek to satisfy their unfulfilled expectations, dreams and desires through their children, especially when their self-esteem is associated to the success of their children (Nunomura \& Oliveira, 2008). When this occurs, that is, when parents live a vicarious existence through the experiences of their offspring, training sessions can become a burden for the athletes and, in some circumstances, for the coaches (McCombs \& Palmer, 2008). In this context, the fact that, as the career of athletes evolved, coaches perceived parents' ambitions and frustrations as less important to the persistence of athletes in the sport may be seen as positive. On the other hand, this decline can also be attributed to the adjustment of parental expectations to the real possibilities of the child over time.

Finally, it is worth mentioning that, as was the case for the athletes, the coaches believed that, for many parents, the practice of gymnastics could facilitate athletes' access to university, legitimizing their continued involvement in the sport. As previously mentioned, the strictness of artistic gymnastic training does not leave athletes much free time to study, and frequently they only access university by obtaining excellent competitive results, which make them eligible for university admission through a special statute endorsed by the Portuguese government. 
Table 4. Motives to persist in women's artistic gymnastics (parents)

\begin{tabular}{|c|c|c|c|c|c|c|c|c|c|c|c|c|c|c|}
\hline \multirow{3}{*}{ Categories } & \multicolumn{7}{|c|}{ At the beginning of the career } & \multicolumn{7}{|c|}{ Throughout the career } \\
\hline & \multicolumn{6}{|c|}{ Frequency } & \multirow[t]{2}{*}{$M$} & \multicolumn{6}{|c|}{ Frequency } & \multirow[t]{2}{*}{$M$} \\
\hline & 6 & 5 & 4 & 3 & 2 & 1 & & 6 & 5 & 4 & 3 & 2 & 1 & \\
\hline outlet for parents' personal frustration & 2 & 2 & 2 & & & 1 & 4.4 & 1 & & 4 & & 1 & 1 & 3.6 \\
\hline ambition of having a daughter in an important position in WAG & 2 & 2 & 2 & & & 1 & 4.4 & 1 & 1 & 3 & & 1 & 1 & 3.7 \\
\hline $\begin{array}{l}\text { WAG as a means of social affirmation (through the daughters' } \\
\text { results) }\end{array}$ & 1 & 3 & 1 & & 1 & 1 & 4.0 & 1 & 2 & 2 & & 2 & 1 & 3.6 \\
\hline $\begin{array}{l}\text { potential of WAG regarding the comprehensive formation of } \\
\text { athletes }\end{array}$ & 3 & 4 & 1 & & & & 5.3 & & 3 & 5 & & & & 4.4 \\
\hline $\begin{array}{l}\text { potential of WAG regarding the development of the athletes' } \\
\text { conditional and coordinative abilities }\end{array}$ & 1 & 4 & 1 & 2 & & & 4.5 & & 3 & 5 & & & & 4.4 \\
\hline Medical advice & & 3 & 1 & & 2 & 1 & 3.4 & & 2 & 1 & & 3 & 1 & 3.0 \\
\hline WAG as a means to fulfill their daughters' free time & 2 & 2 & 4 & & & & 4.8 & & & & & & & --- \\
\hline possible financial benefits & & 1 & 2 & & 1 & 3 & 2.6 & & & 2 & 1 & 2 & 2 & 2.4 \\
\hline possible facilitated access to the university & 2 & 1 & 3 & & 1 & 1 & 4.0 & 2 & 2 & 2 & & & 2 & 4.0 \\
\hline possible social benefits & 1 & 1 & 1 & & 3 & 1 & 3.1 & & & 2 & 1 & & 4 & 2.1 \\
\hline
\end{tabular}

Note. Respondents were asked to use the following scale: 6- extremely relevant; 5- very relevant; 4- relevant; 3neither relevant nor irrelevant; 2- slightly relevant; 1- not relevant

\subsection{Factors of Success in Women's Artistic Gymnastics}

In a last moment, the coaches were enquired about the fact that, in Portugal and throughout the period under review (i.e., 1971-2010), the Portuguese athletes who achieved the best results at the senior level had consistently been champions throughout their entire career, namely at lower age levels. In other words, it seemed that the sporting system implemented in Portugal in the last decades had succeeded in pointing out the best athletes, ensuring their prosperous development until the age of seniors.

In general, the factors evoked by coaches to justify the success of athletes can be grouped into six main aspects: (a) successful competitive results, (b) functional and training management conditions (balance, consistency, and individualization), (c) psychological factors (pleasure, emotional balance), (d) interpersonal relationships within the sport context (technical team, athletes), (e) concern over different domains of life of the athletes (personal, school, family), (f) family support, and, (g) other benefits (social, financial, academic). Overall, these results suggest the existence of different circumstances, eventually converging, which enable a gymnast to rise to an elite level (Louer et al., 2012). However, it is important to analyze these results more deeply (Table 5).

One interesting result concerns the relevance given by coaches to the competitive results, on the one hand, and to the pleasure and satisfaction derived from sport participation, on the other hand. These results are consistent with claims of Coté et al. (2007) that when athletes decide to pursue a performance trajectory in sport, their inherent interest in sport (i.e., fun and enjoyment), needs to be complemented by extrinsic benefits associated with competition and performance (e.g., winning, trophies). Côté et al. also consider, as mentioned previously, that although his kind of performance context generally is not appropriate before the ages of 13-15 years, in sports such as women's gymnastics, where peak performance occurs before maturation, athletes may need this kind of performance environment. Additionally, the results also stress the need to contemplate the individuality of responses to training, planning specific and individual training loads and sequences of training activities (Malina et al., 2013). Similarly, the human and social circumstances surrounding the athletes, whether in the context of sport (coaching staff, teammates, administrators) or family, also seemed essential to the achievement of an elite status. These data are consistent with several studies that have demonstrated the importance, for achieving high levels of performance, of the interpersonal relationship with the coach (Jowett \& Cockerill, 2003; Jowett \& Timson-Katchis, 2005), material and emotional support from parents and expertise and emotional support from the coach (Cogan \& Vidmar, 2000; Fredricks \& Eccles, 2004; Weiss \& Hayashi, 1995; Wuerth et al., 2004), and social relations with teammates (Fraser-Thomas et al., 2005). 
Indeed, in what concerns to the Portuguese reality, it can be important to mention that a recent study also focused in the period time under review (Pereira, Faro, Stotlar, \& Fonseca, in press) revealed that a great percentage of the athletes who won the competitions at the beginning of their careers did it again consistently along their careers until the category of seniors, exhibiting a elevated stability reaching good performances and a high longevity career. Hence, this can be related to the quality of the material, technical, social, psychological and emotional context provided by the responsible persons by their sport training process (i.e., coaches and other club's staff) in supporting and developing their talent, but also to the effective attaining of good performances and sport results.

Table 5. Factors of success in women's artistic gymnastics

\begin{tabular}{|c|c|c|c|c|c|c|c|}
\hline & \multicolumn{6}{|c|}{ Frequency } & \multirow[t]{2}{*}{$M$} \\
\hline & 6 & 5 & 4 & 3 & 2 & 1 & \\
\hline \multicolumn{8}{|l|}{ In general } \\
\hline competitive results & 4 & 4 & & & & & 5.5 \\
\hline relationship with the technical staff & 4 & 4 & & & & & 5.5 \\
\hline small number of athletes who pursue a performance trajectory & 3 & 4 & 1 & & & & 5.3 \\
\hline enjoyment in practicing gymnastics & 4 & 3 & & & 1 & & 5.1 \\
\hline relationship with teammates & 4 & 2 & 1 & 1 & & & 5.1 \\
\hline having one coach throughout the whole competitive career & 1 & 5 & 2 & & & & 4.9 \\
\hline facilitated access to the university & 3 & 3 & 1 & & 1 & & 4.9 \\
\hline familiar support and encouragement & 1 & 4 & 2 & 1 & & & 4.6 \\
\hline financial benefits & & 3 & & & 2 & 2 & 3.0 \\
\hline social benefits & & 3 & & & 2 & 2 & 3.0 \\
\hline \multicolumn{8}{|l|}{ In particular: } \\
\hline attention distributed across all athletes & 5 & 2 & 1 & & & & 5.5 \\
\hline paying particular attention to the whole training process & 4 & 4 & & & & & 5.5 \\
\hline careful management of the balance between training load and rest periods & 4 & 3 & 1 & & & & 5.4 \\
\hline permanent and comprehensive support to the athlete by the technical team & 2 & 6 & & & & & 5.3 \\
\hline permanent and comprehensive support to the athlete by the club entity & & 5 & 1 & & 1 & & 5.1 \\
\hline added care and support to athletes' academic performance & 2 & 5 & 1 & & & & 5.1 \\
\hline priority in managing time and available equipment & 3 & 3 & 1 & 1 & & & 5.0 \\
\hline paying particular attention to the level of stress generated by training loads & 3 & 2 & 3 & & & & 5.0 \\
\hline priority in accessing medical care and physiotherapy & 3 & 3 & 1 & & & 1 & 4.8 \\
\hline paying particular attention to the personal problems of athletes & 3 & 2 & 2 & & 1 & & 4.8 \\
\hline paying particular attention to familiar stability & 1 & 3 & 2 & 2 & & & 4.4 \\
\hline close and systematic relationship with the parents & 1 & 3 & 2 & 1 & 1 & & 4.3 \\
\hline
\end{tabular}

\section{Final Considerations}

The present study sought to study the perception of the best Portuguese coaches of women's artistic gymnasts about the factors influencing athletes' persistence or dropping out the sport. On the one hand, understanding the motivational factors that keep the gymnasts committed to gymnastics can help streamline the training and learning process. On the other hand, the identification of the reasons why gymnasts dropout the sport will permit to select key aspects that should call special attention from the technical team and club administrators, in order to prevent that dropout. Along these lines, Ryska et al. (2002) suggested that identifying these reasons can be 
decisive in order to permit the development of an intervention model whose implementation may promote the early recognition of the intrinsic or extrinsic factors that may point toward a potential dropout and shed light on the motives that might be crucial for ensuring a more consistent commitment. In this sense, the same authors stressed the importance of developing a predictive model that can determine the context and factors more able to influence participation in sport. As follows, the anticipation of the intervention can be a decisive factor in overcoming any problems causing athletes' dissatisfaction. Still, we must take into consideration that, in the present investigation, the results and conclusions are based on the perceptions of coaches regarding the opinion of athletes and their parents, and not on the perceptions of parents and athletes themselves.

In any case, a first consideration concerns the need to individualize the training process, namely regarding specific intensities and emphases of training, to meet the unique and diverse necessities, characteristics and reactions of each athlete. Similarly, coaches should ensure that, in addition to the training itself, the gymnasts are willing to sacrifice their social life and academic to achieve a high competitive level. Their support may be especially important during critical periods such as puberty, when physical, emotional and social changes may have a greater impact on athletes' motivations towards the practice of gymnastics (Lindner, Caine, et al., 1991; Malina, 1999; Malina et al., 2013; Nunomura et al., 2012).

Additionally, considering that the competitive environment (and an eventual lack of competitive success) may also be a source of stress for female gymnasts, it is imperative that coaches provide the support, encouragement, and guidance necessary for athletes to deal with these situations and stay focused on their goals. Accordingly, it is essential that athletes receive a proper structured training directed towards the improvement of their current level of performance, ultimately leading to outstanding results, victories and trophies, but they also need to continue to have fun and enjoy their sporting experience (Coté et al. (2007). As well, the maintenance of good interpersonal relationships with coaches, teammates, and even administrators should not be devalued (Fraser-Thomas et al., 2005; Jowett \& Cockerill, 2003; Jowett \& Timson-Katchis, 2005) since they appeared frequently as reasons for leaving their practice.

Moreover, the ascendancy of parents over their daughters, especially at early ages, can be decisive to understand the decision of persisting or dropping out of women's artistic gymnasts, whether this decision was made by the girls themselves or their parents. To this extent, the results of this study provided support to the importance of coaches being attentive and keep open lines of communication with parents. They can give them some important information (e.g., athlete's motives to practice gymnastics, personal goals), which may be useful in understanding any dissatisfactions or frustrations related, for example, with the demanding training regime in artistic gymnastics - and all the personal, familiar, and academic difficulties arising therefrom - or the parental ambitions about the athletes' future sporting career. Parents should be aware that they may be imposing too many demands on their daughters, and that even if they are driven by good intentions, their involvement can become excessive and negative, becoming a source of pressure rather than a source of support, which can eventually lead to sport dropout (Cogan \& Vidmar, 2000; Fredricks \& Eccles, 2004; Weiss \& Hayashi, 1995; Wuerth et al., 2004).

In short, the attention and reflection upon the numerous factors of instability in women's artistic gymnastics will never be excessive. However, it is important too to keep in mind that several factors not directly related to the practice of women's artistic gymnastics also influence the decision of dropping out of the sport. Additionally, despite the numerous factors that served as grounds for the athletes to give up their gymnastic practice, it is nonetheless interesting to evoke a study in gymnastics by Johns, Lindner, and Wolko (1990), which concluded that dropout assumed a favorable environment. Specifically, athletes reported a positive past involvement, namely regarding their perception of competence and the pleasure derived from their sport participation. Whatever the case may be, the knowledge of the several factors of influence should be used sparingly. In order to guarantee a successful sporting career, a constant subordination to imponderables, particularly at the personal, familiar and sociopolitical level, affects necessarily the consistency of any training process.

\section{References}

Arkaev, L. I., \& Suchilin, N. G. (2004). Gymnastics: How to create champions. Oxford, UK: Meyer \& Meyer Sport.

Atkins, M., Johnson, D. M., Force, E. C., \& Petrie, T. A. (2013). Do I still want to play? Parents' and peers' influences on girls' continuation in sport. Journal of Sport Behavior, 36(4), 329-345.

Bandura, A. (1969). Principles of behavior modification. New York: Holt, Rinehart and Winston.

Bloom, B. S. (Ed.). (1985). Developing talent in young people. New York: Ballantine Books. 
Boufous S., Finch C., \& Bauman, A. (2004). Parental safety concerns: A barrier to sport and physical activity in children? Australian and New Zealand Journal of Public Health, 28(5), 482-486.

Butcher, J., Lindner, K. J., \& Johns, D. P. (2002). Withdrawal from competitive youth sport: A retrospective ten-year study. Journal of Sport Behavior, 25(2), 145-163.

Calvo, T., Cervelló, E., Jiménez, R., Iglesias, D., \& Murcia, J. (2010). Using self-determination theory to explain sport persistence and dropout in adolescent athletes. The Spanish Journal of Psychology, 13(2), 677-684. http://dx.doi.org/10.1017/S1138741600002341

Cogan, K. D., \& Vidmar, P. (2000). Gymnastics. New York, NY: Fitness Information Technology.

Côté, J., Young, B. W., Duffy, P., \& North, J. (2007). Towards a definition of excellence in sport coaching. International Journal of Coaching Science, 1, 3-17.

Čuk, I., Fink, H., \& Leskošek, B. (2012). Modeling the final score in artistic gymnastics by different weights of difficulty and execution. Science of Gymnastics Journal, 1(4), 73-82.

Čuk, I., Pajek, M. B., Jakse, B., Pajek, J., \& Pecek, M. (2012). Morphologic bilateral differences of top level gymnasts. International Journal of Morphology, 30(1), 110-114. http://dx.doi.org/10.4067/S0717-95022012000100019

Delorme, N., Chalabaev, A., \& Raspaud. M. (2011). Relative age is associated with sport dropout: Evidence from youth categories of French basketball. Scandinavian Journal of Medicine Science in Sports, 21(1), 120-128. http://dx.doi.org/10.1111/j.1600-0838.2009.01060.x

Ericsson, K. A., \& Charness, N. (1994). Expert performance: Its structure and acquisition. American Psychologist, 49, 725-747. http://dx.doi.org/10.1037/0003-066X.49.8.725

Erkut, S., \& Tracy, A. J. (2002). Predicting adolescent self-esteem from participation in school sports among Latino subgroups. Hispanic Journal of Behavioral Sciences, 24, 409-429. http://dx.doi.org/10.1177/0739986302238212

Fonseca, A. M., Corte-Real, N., \& Dias, C. (2010). Da participação ao abandono do desporto [From the participation in sport to dropout]. Revista Portuguesa de Ciências do Desporto, 10(2), 96-114.

Fraser-Thomas, J., \& Côté, J. (2009). Understanding adolescents' positive and negative developmental experiences in sport. The Sport Psychologist, 23(1), 3-23.

Fraser-Thomas, J. L., Côté, J., \& Deakin, J. (2005). Youth sport programs: An avenue to foster positive youth development. Physical Education and Sport Pedagogy, 10, 49-70. http://dx.doi.org/10.1080/1740898042000334890

Fraser-Thomas, J., Côté, J., \& Deakin, J. (2008). Examining adolescent sport dropout and prolonged engagement from a developmental perspective. Journal of Applied Sport Psychology, 20, 318-333. http://dx.doi.org/10.1080/10413200802163549

Fredricks, J. A., \& Eccles, J. S. (2004). Parental influences on youth involvement in sports. In M. Weiss (Ed.), Developmental sport and exercise psychology: A lifespan perspective. Morgantown, WV: Fitness Information Technology.

Gould, D., Lauer, L., Rolo, C., Jannes, C., \& Pennisi, N. (2008). The role of parents in tennis success: Focus group interviews with junior coaches. The Sport Psychologist, 22(1), 18-37.

Gould, D., \& Whitley, M. A. (2009). Sources and consequences of athletic burnout among college athletes. Journal of Intercollegiate Sport, 2(1), 16-30.

Johns, D. P., Lindner, K. J., \& Wolko, K. (1990). Understanding attrition in female competitive gymnastics: Applying social exchange theory. Sociology of Sport Journal, 7, 154-171.

Kunješić, M. (2012). Parent's expectations towards children's artistic gymnastics exercise. Science of Gymnastics Journal, 4(2), 65-73.

Light, R. L., \& Lémonie, Y. (2010). A study on children's reasons for joining and remaining in a French swimming club. Asian Journal of Exercise and Sports Science, 7(1), 27-33.

Lincoln, Y., \& Guba, E. (1985). Naturalistic inquiry. Beverly Hills: Sage.

Jowett, S., \& Cockerill, I. M. (2003). Olympic medalists' perspective of the athlete-coach relationship. Psychology of Sport and Exercise, 4, 313-331. http://dx.doi.org/10.1016/S1469-0292(02)00011-0 
Jowett, S., \& Timson-Katchis, M. (2005). Social networks in the sport context: The influences of parents on the coach-athlete relationship. The Sport Psychologist, 19(3), 267-287.

Khan, Z., Haider, Z., \& Ahmed, N. (2011). Gender difference in achievement motivation of intervarsity level, badminton players. Journal of Physical Education and Sport, 11(3), 255.

Kerlinger, F. N. (1980). Metodologia da pesquisa em ciências sociais: Um tratamento conceitual [Methodology of research in social sciences: A conceptual approach]. São Paulo: EPU.

Louer, L. E. A. M., Elferink-Gemser, M. T., \& Visscher, C. (2012). The perfect elite gymnast, does he exist? A systematic review. Annals of Research in Sport and Physical Activity, 3, 39-61.

Le Bars, H., Gernigon, C., \& Ninot, G. (2009) Personal and contextual determinants of elite young athletes' persistence or dropping out over time. Scandinavian Journal of Medicine and Science in Sports, 119, 274-285.

Lindner, K. J., Caine, D. J., \& Johns, D. P. (1991) Withdrawal predictors among physical and performance characteristics of female competitive gymnasts. Journal of Sports Science, 9, 259-272. http://dx.doi.org/10.1080/02640419108729888

Lindner, K. J., Johns, D. P., \& Butcher, J. (1991). Factors withdrawal from youth sport: A proposed model. Journal of Sport Behavior, 14, 3-18.

Malina, R. M. (1999). Growth and maturation of elite female gymnasts: Is training a factor? In B. Zemel, P. B. Eveleth, \& F. E. Johnston (Eds.), Human growth in context. London, UK: Smith-Gordon.

Malina, R. M., Baxter-Jones, A. D. G., Armstrong, N., Beunen, G. P., Caine, D., Daly, R. M., ... Russell, K. (2013). Role of intensive training on growth and maturation in artistic gymnasts. Sports Medicine, 43(9), 783-802. http://dx.doi.org/10.1007/s40279-013-0058-5

McCombs, J., \& Palmer, C. (2008). Win or lose, what counts as success in coaching? Analysing the opinions and aspirations of gymnastics coaches. Journal of Qualitative Research in Sports Studies, 2(1), 115-130.

Munkácsi, I., Kalmár, Z., Hamar, P., Katona, Z., \& Dancs, H. (2011). Role of motivation in artistic gymnastics by results of a questionnaire based international survey. Journal of Human Sport and Exercise, 7, 92-102.

Nunomura, M., Okade, Y., \& Carrara, P. (2008). How much artistic gymnastics coaches about their gymnasts' motivation. Science of Gymnastics Journal, 4(2), 27- 37.

Nunomura, M., \& Oliveira, M. S. (2008). Parents' support in the sports career of young gymnasts. Science of Gymnastics Journal, 5(1), 5-17.

Pereira, A., Faro, A., Stotlar, D., \& Fonseca, A. M. (2013). A retrospective study of the results of the best Portuguese female gymnasts in a period of 40 years. International Journal of Sports Science, 3(6), 204-210.

Pereira, A., Faro, A., Stotlar, D., \& Fonseca, A. M. (in press). What results achieve the best youth athletes when they became seniors? Evidences from a Portuguese female artistic gymnastics 40 years' period. Review of European Studies, 6(2).

Ryan, R. M., \& Deci, E. L. (2000). Intrinsic and extrinsic motivations: Classic definitions and new directions. Contemporary Educational Psychology, 25, 54-67. http://dx.doi.org/10.1006/ceps.1999.1020

Ryska, T. A., Hohensee, D. D., Cooley, D. D., \& Jones, C. C. (2002). Participation motives in predicting sport dropout among Australian youth gymnasts. North American Journal of Psychology, 4(2), 199-210.

Sarrazin, P., Vallerand, R., Guillet, E., Pelletier, L., \& Cury, F. (2002). Motivation and dropout in female handballers: A 21-month prospective study. European Journal of Social Psychology, 32(3), 395-418. http://dx.doi.org/10.1002/ejsp.98

Schunk, D. H., Hanson, A. R., \& Cox, P. D. (1987). Peer-model attributes and children's achievement behaviors. Journal of Educational Psychology, 79, 54-61. http://dx.doi.org/10.1037/0022-0663.79.1.54

Slutzky, C. B., \& Simpkins, S. D. (2009). The link between sports participation and self-esteem: Exploring the mediating role of sport self-concept. Psychology of Sport and Exercise, 10, 381-389. http://dx.doi.org/10.1016/j.psychsport.2008.09.006

Smolevskiy, V., \& Gaverdovskiy, I. (1996) Tratado general de gimnasia artística deportiva [General treaty of Artistic Gymnastics]. Barcelona: Paidotribo.

Ullrich-French, S., \& Smith, A. L. (2006). Perceptions of relationships with parents and peers in youth sport: 
Independent and combined prediction of motivational outcomes. Psychology of Sport and Exercise, 7, 193-214. http://dx.doi.org/10.1016/j.psychsport.2005.08.006

Ullrich-French, S., \& Smith, A. L. (2009). Social and motivational predictors of continued youth sport $\begin{array}{llllll}\text { participation. Psychology of Sport and Exercise, } & \text { 10, 87-95. }\end{array}$ http://dx.doi.org/10.1016/j.psychsport.2008.06.007

Vazou, S., Ntoumanis, N., \& Duda, J. (2005). Peer motivational climate in youth sport: A qualitative inquiry. Psychology of Sport and Exercise, 6, 497-516. http://dx.doi.org/10.1016/j.psychsport.2004.03.005

Vescio, J. A., \& Crosswhite, J. J. (2002). Sharing good practice: Teenage girls, sport and physical activity. Journal of the International Council for Health, Physical Education, Recreation, Sport and Dance, 38, 47-53.

Vescio, J. A., Wilde, K., \& Crosswhite, J. J. (2005). Profiling sport role models to enhance initiatives for adolescent girls in physical education and sport. European Physical Education Review, 11, 153-170. http://dx.doi.org/10.1177/1356336X05052894

Watts, J. (2002). Perspectives on sport specialization. Journal of Physical Education, Recreation and Dance, 73(8), 32-37. http://dx.doi.org/10.1080/07303084.2002.10608327

Weiss, M., \& Hayashi, C. (1995). All in the family: Parent-child influences in competitive youth gymnastics. Pediatric Exercise Science, 7, 36-48.

Weiss, M. R., \& Williams, L. (2004). The why of youth sport involvement: A developmental perspective on motivational processes. In M. R. Weiss (Ed.), Developmental sport and exercise psychology: A lifespan perspective (pp. 223-268). Morgantown, WV: Fitness Information Technology.

Wuerth, S., Lee, J., \& Alfermann, D. (2004). Parental involvement and athletes' career in youth sport. Psychology of Sport and Exercise, 5(1), 21-33. http://dx.doi.org/10.1016/S1469-0292(02)00047-X

\section{Copyrights}

Copyright for this article is retained by the author(s), with first publication rights granted to the journal.

This is an open-access article distributed under the terms and conditions of the Creative Commons Attribution license (http://creativecommons.org/licenses/by/3.0/). 